\section{High-dose lumateperone: A case report}

Lumateperone is a novel antipsychotic that possesses a variety of unique receptor affinities. The recommended dose of lumateperone is $42 \mathrm{mg} / \mathrm{d}$. In clinical trials, reductions in Positive and Negative Syndrome Scale scores observed with lumateperone, $28 \mathrm{mg} / \mathrm{d}$ and $84 \mathrm{mg} / \mathrm{d}$, failed to separate from placebo. ${ }^{1}$ However, in these trials, safety profiles were similar for all 3 doses.

Despite the popular understanding of lumateperone's "unexplained narrow therapeutic window," ${ }^{2}$ we report the case of a patient with schizophrenia who responded well to lumateperone, $84 \mathrm{mg} / \mathrm{d}$, without adverse effects or EKG changes.

Case report. Mr. W, age 26, has treatment-resistant schizophrenia (paranoid type). He failed to achieve remission on fluphenazine (10 to $25 \mathrm{mg} / \mathrm{d}$ ), perphenazine (4 to $24 \mathrm{mg} / \mathrm{d}$ ), risperidone (started at $4 \mathrm{mg} / \mathrm{d}$ and increased to $8 \mathrm{mg} / \mathrm{d})$, and olanzapine $(15,20$, and $25 \mathrm{mg} / \mathrm{d}$ ). None of these medications eliminated his auditory or visual hallucinations. His response was most robust to perphenazine, as he reported a $50 \%$ reduction in the frequency of auditory hallucinations and a nearcomplete resolution of visual hallucinations (once or twice per week), but he never achieved full remission.

We started lumateperone, $42 \mathrm{mg} / \mathrm{d}$, without a cross-taper. After 4 weeks of partial response, the patient escalated his dose to $84 \mathrm{mg} / \mathrm{d}$ on his own. At a follow-up visit 3.5 weeks after this selfdirected dose increase, $\mathrm{Mr}$. W reported a complete resolution of his auditory and visual hallucinations.

Six months later, Mr. W continued to receive lumateperone, $84 \mathrm{mg} / \mathrm{d}$, without extrapyramidal symptoms, tardive dyskinesia, or other adverse effects. His QTc showed no significant change (410 ms vs $412 \mathrm{~ms}$ ).

Although some studies indicate a possible "therapeutic window" for lumateperone dosing, clinicians should not deprive patients who partially respond to the recommended $42 \mathrm{mg} / \mathrm{d}$ dose of the opportunity for additional benefit through dose escalation. Due to the vagaries of psychiatric pathology, and unique profiles of metabolism and receptor sensitivity, there will always be patients who may require higher-than-recommended doses of lumateperone, as with all other agents.

Andrew Farah, MD, DFAPA Associate Residency Director Cone Behavioral Health Greensboro, North Carolina

Disclosure: The author is a speaker for Intra-Cellular Therapies, the manufacturer of lumateperone.

\section{References}

1. Lieberman JA, Davis RE, Correll CU, et al. ITI007 for the treatment of schizophrenia: a 4-week randomized, double-blind, controlled trial. Biol Psychiatry. 2016;79(12):952-961. doi: 10.1016/j. biopsych.2015.08.026

2. Kantrowitz JT. The potential role of lumateperone-something borrowed? something new? JAMA Psychiatry. 2020;77(4):343-344. doi:10.1001/jamapsychiatry.2019.4265

doi: $10.12788 /$ cp.0118

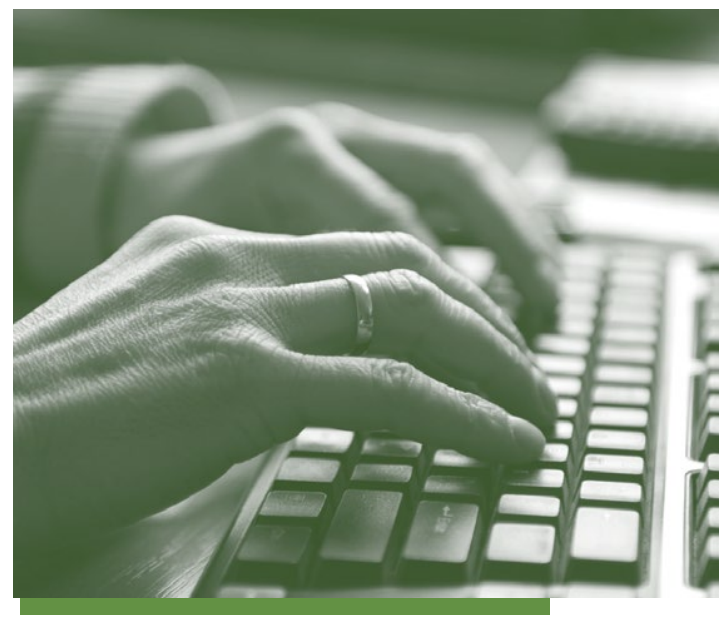

Keep in touch!

The Editors welcome your letters on what you've read in CURREnT Psychiatry

Write to: letters@currentpsychiatry.com

OR

Comments \& Controversies

CURRENT PsychiatRY

7 Century Drive, Suite 302

Parsippany, NJ 07054

All letters are subject to editing. 